Check for updates

Cite this: RSC Adv., 2017, 7, 54002

\title{
Synthesis of all-inorganic $\mathrm{CsPb}_{2} \mathrm{Br}_{5}$ perovskite and determination of its luminescence mechanism $\uparrow$
}

\author{
Jing Li, ${ }^{a}$ Huijie Zhang, ${ }^{a}$ Song Wang, ${ }^{b}$ Debing Long, ${ }^{a}$ Mingkai Li, ${ }^{a}$ Yizhong Guo, ${ }^{a}$ \\ Zhicheng Zhong, ${ }^{a}$ Kaifeng Wu, ${ }^{c}$ Duofa Wang ${ }^{\text {DD }}{ }^{* a}$ and Tianjin Zhang*a
}

\begin{abstract}
All-inorganic cesium lead halide perovskite materials, such as $\mathrm{CsPbBr}$ and $\mathrm{CsPb}_{2} \mathrm{Br}_{5}$, have drawn immense attention recently due to their potential applications in optoelectronics. However, unlike the extensivelystudied $\mathrm{CsPbBr}_{3}$, many of the fundamental properties of $\mathrm{CsPb}_{2} \mathrm{Br}_{5}$ remain unclear, such as its electronic structure and photoluminescence $(\mathrm{PL})$ mechanism. In this work, we developed a novel environmentally friendly chemical method to synthesize $\mathrm{CsPb}_{2} \mathrm{Br}_{5}$, where only water and ethanol were used as solvents. The optical property and electronic structure of $\mathrm{CsPb}_{2} \mathrm{Br}_{5}$ were then examined both experimentally and theoretically. For the first time we found that the band-edge emission of $\mathrm{CsPb}_{2} \mathrm{Br}_{5}$ was not in the visible range as reported in the literature but rather located in the ultraviolet range. By monitoring the $\mathrm{PL}$ property during phase conversion between $\mathrm{CsPb}_{2} \mathrm{Br}_{5}$ and $\mathrm{CsPbBr}_{3}$, we propose that previously-reported visible emission might be due to the involvement of $\mathrm{CsPbBr}_{3}$ during sample preparation. Overall, this study presents a novel green method for the preparation of $\mathrm{CsPb}_{2} \mathrm{Br}_{5}$ and clarifies the optical properties and electronic structure of $\mathrm{CsPb}_{2} \mathrm{Br}_{5}$
\end{abstract}

Received 27th September 2017 Accepted 18th November 2017

DOI: 10.1039/c7ra10693a

rsc.li/rsc-advances

Niu et al. ${ }^{6}$ Many efforts are being attempted to mitigate this

\section{Introduction}

In the recent years, newly emerging metal halide perovskite crystals, in particular organic-inorganic perovskites such as $\mathrm{CH}_{3} \mathrm{NH}_{3} \mathrm{PbX}_{3}(\mathrm{X}=\mathrm{Cl}, \mathrm{Br}$, and $\mathrm{I})$, have attracted tremendous scientific attention, thanks to the rapid development of perovskite solar cells whose power conversion efficiency already exceeds $20 \%$ since the first report of $3.81 \%$ in the year of 2009. ${ }^{1,2}$ In addition to the applications in photovoltaics, perovskites are also reported in high-efficiency light emitting diodes (LEDs), lasers and photodetectors. From the standpoint of practical application, however, hybrid organic-inorganic perovskites suffer from low environmental- and photo-stability due to their undesirable reaction with water and degradation under UV light irradiation. $^{3-5}$ Perovskite solar cells start to degrade within several hours without encapsulation; the chemical processes that cause the degradation of perovskite films were reviewed by

${ }^{a}$ Hubei Collaborative Innovation Center for Advanced Organic Chemical Materials, Ministry of Education, Key Laboratory of Green Preparation and Application for Materials, Hubei Provincial Key Laboratory of Polymers, Department of Materials Science and Engineering, Hubei University, Wuhan 430062, People's Republic of China.E-mail:duofawang@hotmail.com; zhangtj@hubu.edu.cn

${ }^{b}$ Hubei Key Laboratory of Low Dimensional Optoelectronic Materials and Devices, Hubei University of Arts and Science, Xiangyang, Hubei 441053, China

'State Key Laboratory of Molecular Reaction Dynamics, Dalian Institute of Chemical Physics, Chinese Academy of Sciences, 457 Zhongshan Road, Dalian 116023, China

$\dagger$ Electronic supplementary information (ESI) available: Full video of the chemical reaction; energy dispersive X-spectroscopy of $\mathrm{CsPb}_{2} \mathrm{Br}_{5}$; total energy calculation of unit cell for each reactant and the resultant chemical eqn (2). See DOI: 10.1039/c7ra10693a degradation issue but with very limited success. ${ }^{7}$ As a type of perovskite material, the all-inorganic perovskites have recently been proposed as promising candidates for optoelectronics because of their higher chemical stability as compared to their hybrid organic-inorganic counterparts. ${ }^{8-10}$ Cesium lead halide $\left(\mathrm{CsPbX}_{3}, \mathrm{X}=\mathrm{Cl}, \mathrm{Br}\right.$, and $\left.\mathrm{I}\right)$ is the most widely reported material, which was typically prepared in the range of $140-200{ }^{\circ} \mathrm{C}$ by wet chemical method..$^{11} \mathrm{~A}$ variety of optoelectronic devices based on $\mathrm{CsPbX}_{3}$ have been reported.

Very recently, a new type of inorganic perovskite material, $\mathrm{CsPb}_{2} \mathrm{Br}_{5}$, has been found to also exhibit superior optical property and potential application in optoelectronic device. ${ }^{12-15}$ Especially interesting is that unlike $\mathrm{CsPbBr}_{3}$ that requires high temperature for the synthesis, $\mathrm{CsPb}_{2} \mathrm{Br}_{5}$ can be prepared in a facile way at room temperature, which is very attractive for the future applications. Yu et al. first reported on the synthesis of $\mathrm{CsPb}_{2} \mathrm{Br}_{5}$ and its efficient photoluminescence (PL) in the visible region $(512 \mathrm{~nm})$ with a quantum yield of $87 \% .^{12}$ Zhou et al. demonstrated visible amplified spontaneous emission (ASE) from $\mathrm{CsPb}_{2} \mathrm{Br}_{5}$ microplates with very low pump threshold. ${ }^{13}$ Sun et al. reported the formation of $\mathrm{CsPb}_{2} \mathrm{Br}_{5}$ as a by-product during the preparation of $\mathrm{CsPbBr}_{3}$ and also noted an enhancement in the light emission efficiency of $\mathrm{CsPbBr}_{3}$ LED due to the generation of $\mathrm{CsPb}_{2} \mathrm{Br}_{5} \cdot{ }^{14}$ However, there is a debate about the luminescence mechanism of inorganic $\mathrm{CsPb}_{2} \mathrm{Br}_{5}$ perovskite. Based on the density functional theory (DFT) simulation as well as experimental work, it has been noted that the visible light emission gradually decreases and ultimately disappears 
accompanying the phase conversion from $\mathrm{CsPbBr}_{3}$ to $\mathrm{CsPb}_{2} \mathrm{Br}_{5}$. Jiang et al. emphasized that $\mathrm{CsPb}_{2} \mathrm{Br}_{5}$ is an indirect bandgap semiconductor and PL-inactive. ${ }^{15}$ Therefore, fundamental research on the optical property and electronic structure of $\mathrm{CsPb}_{2} \mathrm{Br}_{5}$ is imperative, which is important to explain the current controversial experimental observations and to explore its mechanism of luminescence.

In this context, we report a facile method on the fabrication of tetragonal perovskite, $\mathrm{CsPb}_{2} \mathrm{Br}_{5}$ at ambient temperature as well as its phase conversion between $\mathrm{CsPb}_{2} \mathrm{Br}_{5}$ and $\mathrm{CsPbBr}_{3}$. By precisely controlling the phase conversion and monitoring the evolution of PL property, we find that $\mathrm{CsPb}_{2} \mathrm{Br}_{5}$ has a bandgap of $3.13 \mathrm{eV}$ and correspondingly exhibits a band-edge emission in the ultraviolet region, and hence, the frequently observed visible $\mathrm{PL}$ peak can be attributed to the $\mathrm{CsPbBr}_{3}$ by-product in $\mathrm{CsPb}_{2} \mathrm{Br}_{5}$. These results not only clarify the luminescence mechanism of $\mathrm{CsPb}_{2} \mathrm{Br}_{5}$ being under debate, but also provide valuable insights for the development of $\mathrm{CsPb}_{2} \mathrm{Br}_{5}$ based photoelectric devices.

\section{Experimental}

\section{Synthesis of $\mathrm{CsPb}_{2} \mathrm{Br}_{5}$}

$\mathrm{CsPb}_{2} \mathrm{Br}_{5}$ nanoplates were synthesized by chemical precipitation conducted at room temperature. Firstly, purified water and ethanol were mixed to obtain the solvent mixture (total volume $\left.=2 \mathrm{ml}, V_{\mathrm{H}_{2} \mathrm{O}}: V_{\mathrm{EtOH}}=1: 3\right)$. CsAc $(1 \mathrm{mmol})$ was added into the above solution and dissolved completely. $\mathrm{PbBr}_{2}(2.5 \mathrm{mmol})$ was added into CsAc solution and mixed mechanically which resulted in the formation of $\mathrm{CsPb}_{2} \mathrm{Br}_{5}$ as a precipitate at the bottom of the solution. The precipitate was further treated with $\mathrm{HBr}$ to remove the impurities and then washed with water.

\section{Characterization of $\mathrm{CsPb}_{2} \mathrm{Br}_{5}$}

The crystal structure was measured by using a X-ray diffractometer (Bruker D8 Advance) with $\mathrm{Cu}-\mathrm{K} \alpha$ radiation $(\lambda=1.5406 \AA)$. The SEM and EDS were measured using JSM7100F. Absorption spectra were obtained by UV-Visible-NIR Spectrophotometer (SHIMADZU UV-3600). Edinburgh FLS 980 was used to measure the steady-state fluorescence spectrum.

\section{First principle calculations}

First-principle calculations were performed on the basis of density functional theory (DFT) as implemented in the QUANTUM ESPRESSO code. The exchange and correlation terms were described using general gradient approximation (GGA) of Perdew-Burke-Ernzerhof (PBE). The energy cutoff for the plane wave basis set was $600 \mathrm{eV}$. The accuracy of selfconsistent field (SCF) energy convergence and the convergence accuracy of the internal stress of crystal is less than $1.4 \times$ $10^{-5} \mathrm{eV}$ per atom and $0.05 \mathrm{GPa}$, respectively. For the different alloy configurations, Monkhorst-Pack grids were determined automatically for Brillouin zone integration and KPPRA parameter was set to 1000.

\section{Results and discussion}

The $\mathrm{CsPb}_{2} \mathrm{Br}_{5}$ was synthesized via a chemical precipitation method and the details are described in the Experimental Section. Briefly, cesium acetate (CsAc) was first dissolved in a mixed solvent of purified water and ethanol and $\mathrm{PbBr}_{2}$ solid was added into the above solvent mixture. As shown by the video (Movie S1) in the ESI, $\uparrow$ the reaction is very fast and efficient and results in the formation of $\mathrm{CsPb}_{2} \mathrm{Br}_{5}$ just several seconds after the addition of $\mathrm{PbBr}_{2}$ which "emits" green light under UV light irradiation. As $\mathrm{CsPb}_{2} \mathrm{Br}_{5}$ does not dissolve well in water, a precipitate was obtained at the bottom. The obtained precipitate was further treated with $\mathrm{HBr}$ to remove the impurities and then washed with water. We propose the following equations representing the chemical reactions involved in the synthesis, where CsAc is hydrolyzed at first to generate $\mathrm{CsOH}$, which then reacts with $\mathrm{PbBr}_{2}$ :

$$
\begin{gathered}
\mathrm{CsAc}+\mathrm{H}_{2} \mathrm{O} \rightarrow \mathrm{CsOH}+\mathrm{HAc} \\
\mathrm{CsOH}+\mathrm{PbBr}_{2} \rightarrow \mathrm{CsPb}_{2} \mathrm{Br}_{5}+\mathrm{Pb}(\mathrm{OH}) \mathrm{Br} \\
\mathrm{Pb}(\mathrm{OH}) \mathrm{Br}+\mathrm{HBr} \rightarrow \mathrm{PbBr}_{2}+\mathrm{H}_{2} \mathrm{O}
\end{gathered}
$$

To investigate the possibility of eqn (2), which is crucial for the formation of $\mathrm{CsPb}_{2} \mathrm{Br}_{5}$, the total energy $\left(E_{\mathrm{t}}\right)$ of the chemical reaction was calculated by employing first principles. The change in total energy $\left(\Delta E_{\mathrm{t}}\right)$ of $-4.558 \mathrm{eV}$ indicates that the reaction is exothermic and should occur spontaneously. The details of calculations can be found in the ESI (Table S1 $\dagger$ ). The chemical reaction eqn (1) was confirmed experimentally that the $\mathrm{PH}$ value was changed to 9 after the CsAc is added to the mixture solvent of water and ethanol.

Fig. 1a shows the scanning electron microscopy (SEM) image, which illustrates that the formed $\mathrm{CsPb}_{2} \mathrm{Br}_{5}$ nanoparticles are prone to aggregate to form a cluster. Energy dispersive spectroscopy (EDS) analysis (Fig. S1 in the ESI $\dagger$ ) reveals the molar ratio of $\mathrm{Cs} / \mathrm{Pb} / \mathrm{Br}$ to be $1 / 2.1 / 5.9$, which agrees well with the stoichiometry of the compound.

The crystalline structure was characterized by powder X-ray diffraction (PXRD) (Fig. 1b). As shown in this figure, all the diffraction peaks match well with the standard tetragonal phase of $\mathrm{CsPb}_{2} \mathrm{Br}_{5}$ (PDF\#25-0211). The presence of small amounts of $\mathrm{PbBr}_{2}$ has also been noted. The microstructure of $\mathrm{CsPb}_{2} \mathrm{Br}_{5}$ was further characterized by TEM, as shown in Fig. 1c and d. High resolution TEM reveals the crystalline $\mathrm{CsPb}_{2} \mathrm{Br}_{5}$ phase with the lattice fringe of $0.744 \mathrm{~nm}$, corresponding to the (002) plane of $\mathrm{CsPb}_{2} \mathrm{Br}_{5}$. This is well consistent with the XRD results.

Fig. 2a-e illustrate the detailed structure of $\mathrm{CsPb}_{2} \mathrm{Br}_{5}$. The tetragonal phase of $\mathrm{CsPb}_{2} \mathrm{Br}_{5}$ belongs to the space group of $I 4 / \mathrm{mcm}$ and it exhibits a sandwich structure consisting of $\left[\mathrm{Pb}_{2} \mathrm{Br}_{5}\right]^{-}$layers and intercalated $\mathrm{Cs}^{+}$. The $\mathrm{Cs}^{+}$ions stay in the gaps between the two rectangular pyramid grooves, which have a staggered arrangement. There are two types of bromine atoms occupying different positions in the cell which combine with lead atoms forming a $\mathrm{Pb}-\mathrm{Br}$ coordination polyhedron. One lead atom and eight bromine atoms make up a hendecahedron. 

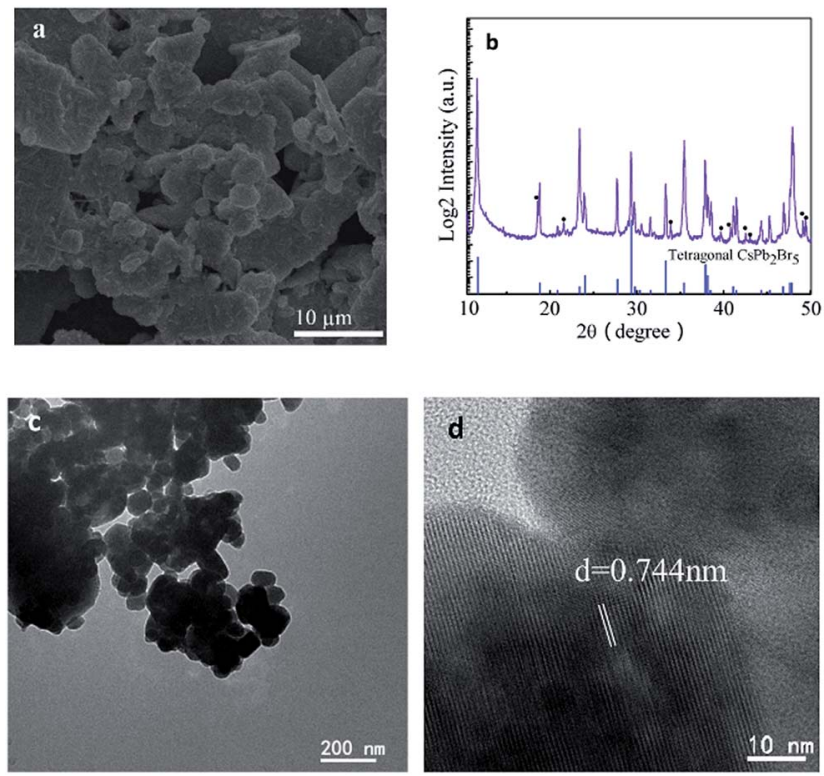

Fig. 1 (a) SEM images of $\mathrm{CsPb}_{2} \mathrm{Br}_{5}$ cluster. (b) PXRD pattern of tetragonal $\mathrm{CsPb}_{2} \mathrm{Br}_{5}$ particles (black dots represent $\mathrm{PbBr}_{2}$ ). The intensity is in logarithmic scale. (c) Low-resolution, and (d) high resolution lattice resolved TEM image of a representative $\mathrm{CsPb}_{2} \mathrm{Br}_{5}$ cluster.

Combining ball-and-stick models and polyhedral models exhibit the tetragonal phase of $\mathrm{CsPb}_{2} \mathrm{Br}_{5}$ with an interesting sandwich structure. DFT-based first-principles calculations (see details in the Experimental Section) determined the lattice constants as: $a=b=0.86 \mathrm{~nm}$ and $c=1.59 \mathrm{~nm}$.

The optical absorption and emission spectra of $\mathrm{CsPb}_{2} \mathrm{Br}_{5}$ are shown in Fig. 3a. An obvious absorption edge at $380 \mathrm{~nm}$ could be noted which is different from the previously reported value of 520 nm. ${ }^{12,13}$ In the PL spectrum, the two luminescence peaks at $385 \mathrm{~nm}$ and $460 \mathrm{~nm}$ were detected which exhibit a small Stokes shift as compared to absorption. Fig. 3b gives the plots of $(A h \nu)^{1 / 2} v s$. photo energy, from which a bandgap of $3.13 \mathrm{eV}$ can be found for $\mathrm{CsPb}_{2} \mathrm{Br}_{5}$.

To reconcile the absorption and emission properties of $\mathrm{CsPb}_{2} \mathrm{Br}_{5}$ observed here with previous reports (band edge at $\sim 515 \mathrm{~nm}$ ), we scrutinized the absorption spectrum and indeed found another weak absorption edge at $\sim 515 \mathrm{~nm}$ as highlighted with the red circle in Fig. 3a. Since two absorption edges were observed, a reasonable assumption is that the one observed at $515 \mathrm{~nm}$ is due to an impurity, the most possible origin of which would be $\mathrm{CsPbBr}_{3}$ considering that there exists a phase transition between $\mathrm{CsPbBr}_{3}$ and $\mathrm{CsPb}_{2} \mathrm{Br}_{5}$ as well as that the absorption edge of $\mathrm{CsPbBr}_{3}$ is well known to be located at $515 \mathrm{~nm}$ and $\mathrm{PbBr}_{2}$ does not show light emission at room temperature. ${ }^{16,17}$

To confirm the above speculation, we annealed $\mathrm{CsPb}_{2} \mathrm{Br}_{5}$ sample and measured the phase transition and meanwhile monitored the associated absorption and PL properties. Fig. 4a is the PXRD data of $\mathrm{CsPb}_{2} \mathrm{Br}_{5}$ annealed at different temperatures. As shown in this figure, the diffraction peaks corresponding to $\mathrm{CsPbBr}_{3}$ and $\mathrm{PbBr}_{2}$ were detected when the sample

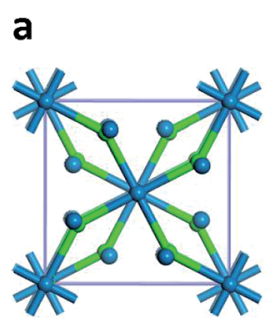

b
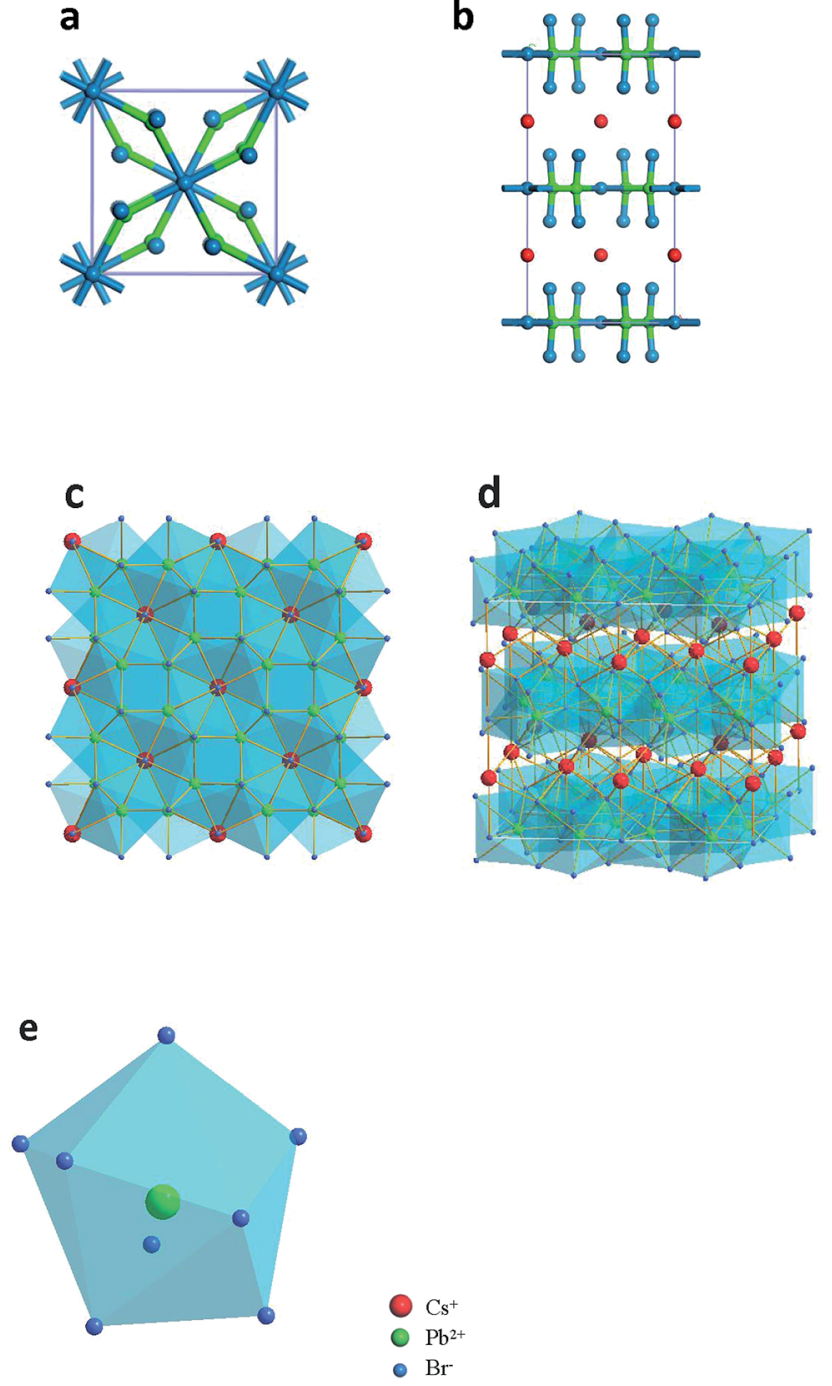

Fig. 2 Crystal structure of tetragonal $\mathrm{CsPb}_{2} \mathrm{Br}_{5}$. (a), (b) Top and side views of ball-and-stick models for $\mathrm{CsPb}_{2} \mathrm{Br}_{5}$ unit cell. (c), (d) Top and side views of polyhedral models for the tetragonal structure of $\mathrm{CsPb}_{2} \mathrm{Br}_{5}$, with sandwiched structure by alternating $\mathrm{Cs}^{+}$and $\left(\mathrm{Pb}_{2} \mathrm{Br}_{5}\right)^{-}$ layers. (e) Schematic of $\mathrm{Pb}-\mathrm{Br}$ hendecahedron (red ball: $\mathrm{Cs}^{+}$, green ball: $\mathrm{Pb}^{2+}$, blue ball: $\mathrm{Br}^{-}$).

was treated with thermal annealing, and the intensity of the corresponding diffraction peaks increased with annealing temperature. It indicates that part of the $\mathrm{CsPb}_{2} \mathrm{Br}_{5}$ is decomposed into $\mathrm{CsPbBr}_{3}$ as shown by eqn (4),

$$
\mathrm{CsPb}_{2} \mathrm{Br}_{5} \rightarrow \mathrm{CsPbBr}_{3}+\mathrm{PbBr}_{2}
$$

XPS characterization results in Fig. $4 \mathrm{~b}$ reveals that there is no obvious peak shift of binding energy after the thermal annealing due to the same chemical valence of $\mathrm{Pb}$ in $\mathrm{CsPb}_{2} \mathrm{Br}_{5}$ and $\mathrm{CsPbBr}_{3}$. The microstructure and composition of the annealed sample was further revealed by TEM and shown in Fig. 4c and d. The $\mathrm{CsPb}_{2} \mathrm{Br}_{5}$ and $\mathrm{CsPbBr}_{3}$ are clearly observed in the high resolution TEM, which consistent with XRD results. 

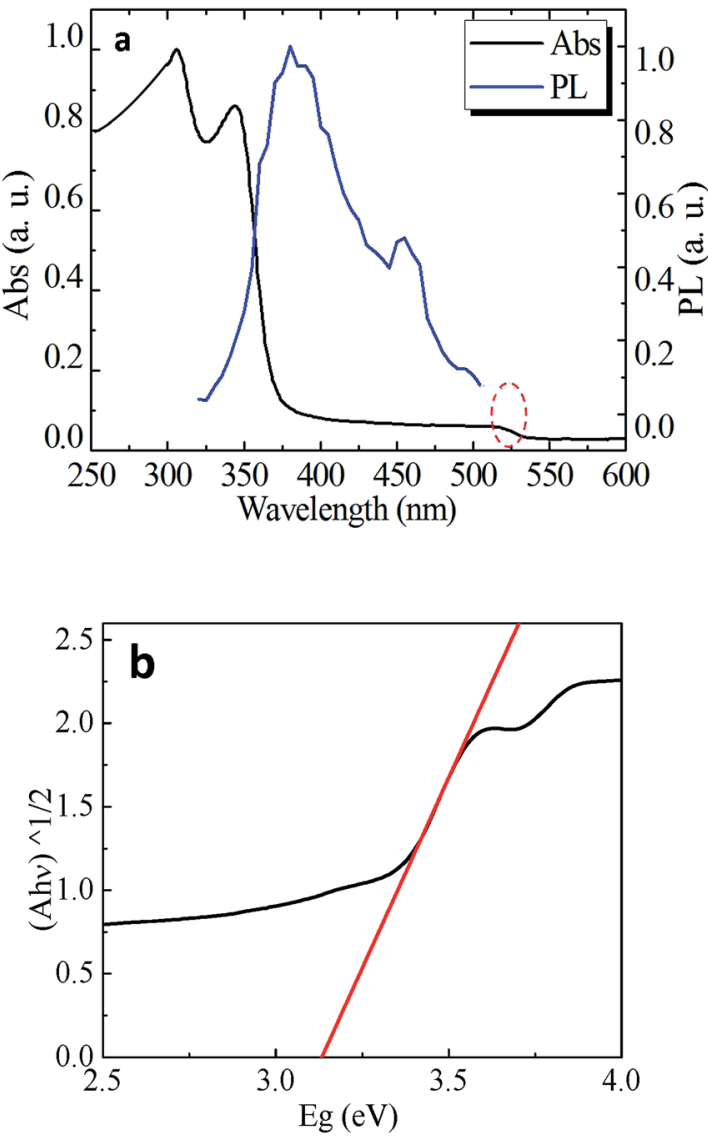

Fig. 3 (a) Absorption (black) and PL spectra (blue) of $\mathrm{CsPb}_{2} \mathrm{Br}_{5}$ particles, the $\mathrm{PL}$ spectrum under $250 \mathrm{~nm}$ excitation. (b) Corresponding $(A h \nu)^{1 / 2}$ vs. energy $(h \nu)$ curve of $\mathrm{CsPb}_{2} \mathrm{Br}_{5}$. The optical band gap of $\mathrm{CsPb}_{2} \mathrm{Br}_{5}$ is measured to be $\sim 3.13 \mathrm{eV}$.

Fig. 5 a shows the notable increase in absorption between 380 and $530 \mathrm{~nm}$. This absorption band grows with increasing annealing temperature. When the sample was annealed at $400{ }^{\circ} \mathrm{C}$, the absorption edge at $380 \mathrm{~nm}$ was not distinguishable any more due to being overwhelmed by the absorption of $\mathrm{CsPbBr}_{3}$, which might explains the absence of the absorption edge at $380 \mathrm{~nm}$ as observed in previous reports. The consistency between the PXRD and absorption results demonstrates that the absorption at $515 \mathrm{~nm}$ is indeed induced by $\mathrm{CsPbBr}_{3}$.

The PL spectra in Fig. 5b also shows the luminescence peaks corresponding to $\mathrm{CsPbBr}_{3}{ }^{\mathbf{1 1 , 1 8}}$ In addition, the position of PL peak shifts from 515 to $530 \mathrm{~nm}$ with thermal annealing. This is ascribed to the size effect. In the as-grown sample, the contents of $\mathrm{CsPbBr}_{3}$ is too low to be detected by XRD and the grain size must be very small. Whereas, it could grown into larger size with the decomposition of $\mathrm{CsPb}_{2} \mathrm{Br}_{5}$ after thermal annealing. The band structure of $\mathrm{CsPb}_{2} \mathrm{Br}_{5}$ was investigated theoretically by first principles calculations based on DFT (Fig. 5c). It could be seen that $\mathrm{CsPb}_{2} \mathrm{Br}_{5}$ exhibits an indirect band gap of $3.079 \mathrm{eV}$ with the conduction band minimum and valence band maximum at the $\Gamma$ and $K$ points respectively. The obtained bandgap value agrees reasonably well with the value as obtained from the absorption spectrum.
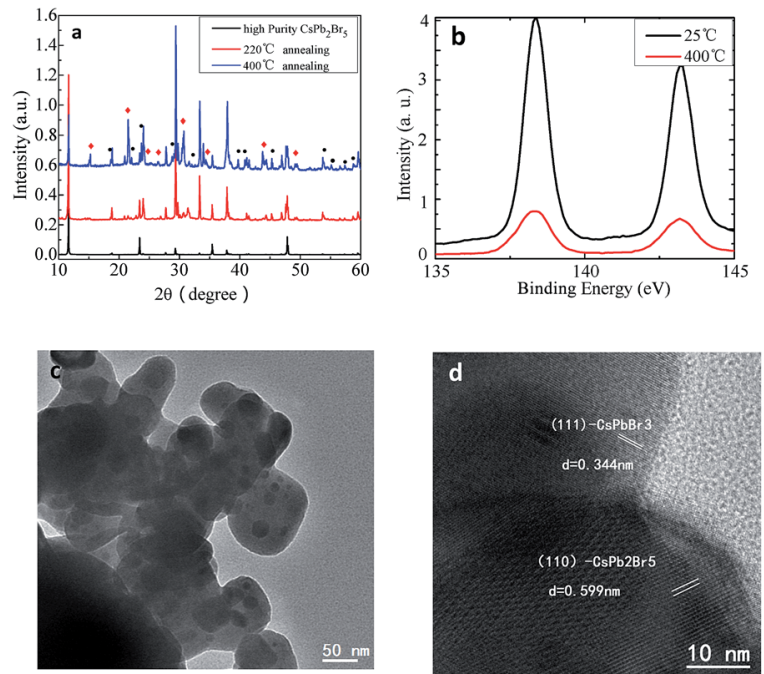

Fig. 4 (a) PXRD pattern of tetragonal $\mathrm{CsPb}_{2} \mathrm{Br}_{5}$ particles after annealing at different temperatures (red squares represent $\mathrm{CsPbBr}_{3}$ (PDF\#18-0364), black dots represent $\mathrm{PbBr}_{2}$ ), sample 1 is of high purity $\mathrm{CsPb}_{2} \mathrm{Br}_{5}$ (black) without annealing, sample 2 is $\mathrm{CsPb}_{2} \mathrm{Br}_{5}$ after annealing at $220{ }^{\circ} \mathrm{C}$ (red), sample 3 is $\mathrm{CsPb}_{2} \mathrm{Br}_{5}$ after annealing at $400{ }^{\circ} \mathrm{C}$ (blue). (b) XPS spectra of the pure as-grown $\mathrm{CsPb}_{2} \mathrm{Br}_{5}$ and annealed composite $\mathrm{CsPb}_{2} \mathrm{Br}_{5}-\mathrm{CsPbBr}_{3}$ with element $\mathrm{Pb} 4 \mathrm{f}$. (c) Lowresolution, and (d) high-resolution TEM image of a representative $\mathrm{CsPb}_{2} \mathrm{Br}_{5}$ cluster after annealing at $400{ }^{\circ} \mathrm{C}$.
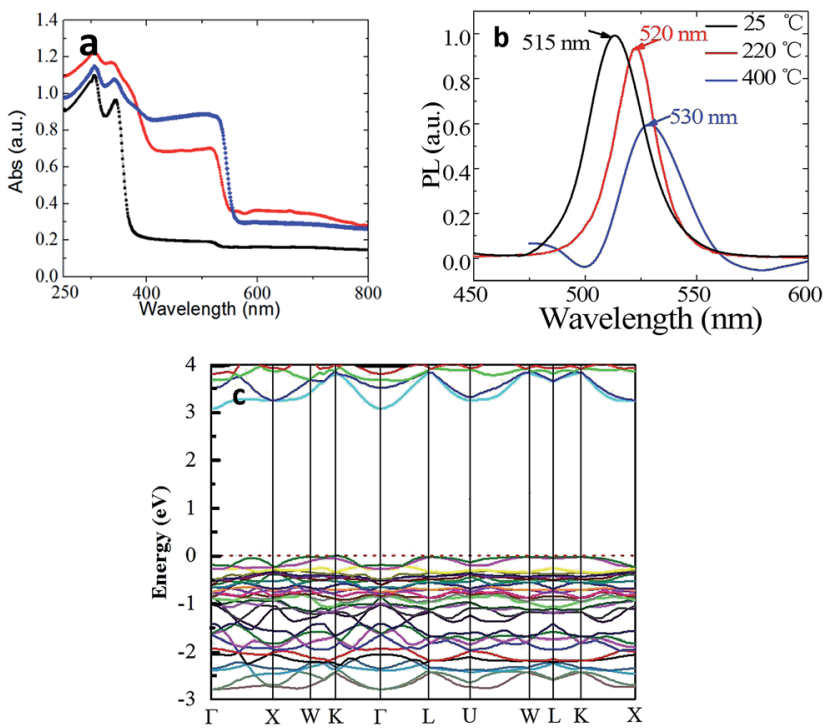

Fig. 5 (a), (b) Absorption and PL spectra of $\mathrm{CsPb}_{2} \mathrm{Br}_{5}$ particles. The black, red and blue represents the sample of as-grown, annealed at $220{ }^{\circ} \mathrm{C}$, and $400{ }^{\circ} \mathrm{C}$, respectively. The $\mathrm{PL}$ excitation is $400 \mathrm{~nm}$. (c) DFT calculated band structure of $\mathrm{CsPb}_{2} \mathrm{Br}_{5}$ with a bandgap of $3.079 \mathrm{eV}$.

Moreover, we investigated the partial cation exchange of Cs by $\mathrm{Rb}$ to from $\mathrm{Cs}_{1-x} \mathrm{Rb}_{x} \mathrm{~Pb}_{2} \mathrm{Br}_{5}$. When $\mathrm{RbAc}$ was introduced together with CsAc, $\mathrm{Cs}_{1-x} \mathrm{Rb}_{x} \mathrm{~Pb}_{2} \mathrm{Br}_{5}$ compound was successfully synthesized. As shown in Fig. 6a, the ion exchange by $\mathrm{Rb}$ did not change the crystalline structure but the lattice constant was reduced due to the smaller atomic radius of $\mathrm{Rb}$. Fig. $6 \mathrm{~b}$ plots the 

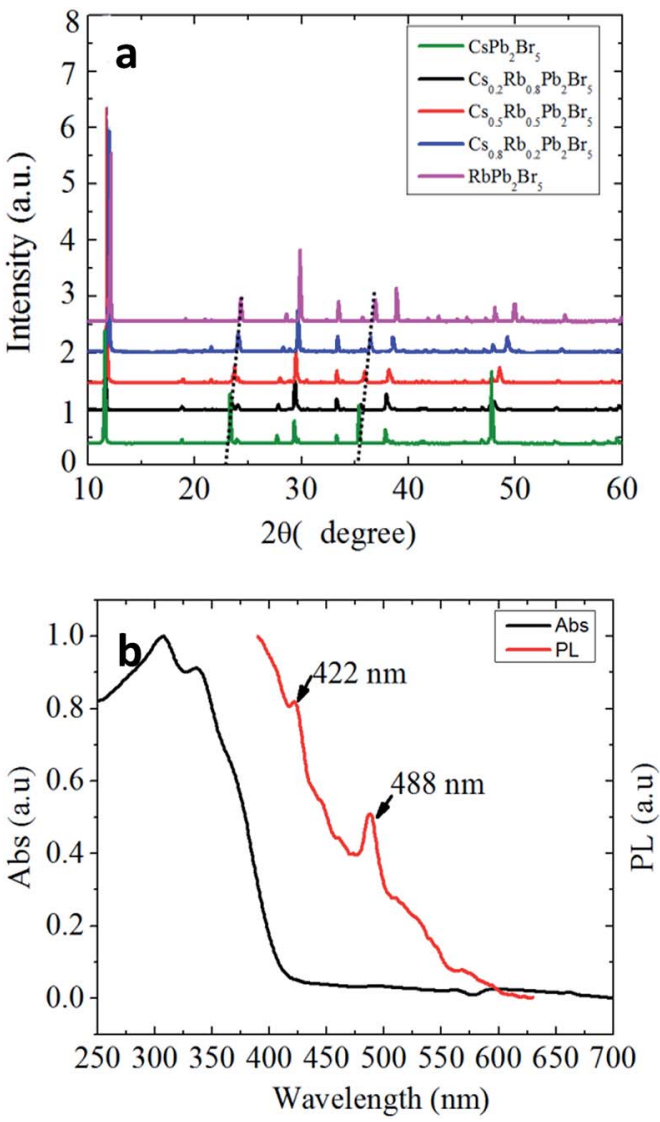

Fig. 6 (a) PXRD patterns of the parent $\mathrm{CsPb}_{2} \mathrm{Br}_{5}$ particles and anion exchanged samples with increasing quantities of anion-exchange of $\mathrm{Rb}^{-}$. (b) Absorption (black) and $\mathrm{PL}$ spectra (red) of $\mathrm{RbPb}_{2} \mathrm{Br}_{5}$, the $\mathrm{PL}$ spectrum under $250 \mathrm{~nm}$ excitation.

absorption and PL spectra of $\mathrm{RbPb}_{2} \mathrm{Br}_{5}$. Compared to $\mathrm{CsPb}_{2} \mathrm{Br}_{5}$ in Fig. 3a, the absorption and PL are red-shifted, indicating that ion exchange of A-site could be utilized to tune the bandgap and extend the optical response of $\mathrm{Cs}_{1-x} \mathrm{Rb}_{x} \mathrm{~Pb}_{2} \mathrm{Br}_{5}$ to the visible range.

\section{Conclusions}

In conclusion, we developed a novel environmentally green method to synthesize $\mathrm{CsPb}_{2} \mathrm{Br}_{5}$, where only water and ethanol were used as solvents. The optical property and electronic structure of $\mathrm{CsPb}_{2} \mathrm{Br}_{5}$ have been explored experimentally as well as theoretically. For the first time, we observed the ultraviolet emission from $\mathrm{CsPb}_{2} \mathrm{Br}_{5}$. Employing the technique of UV-vis absorption, PL, and first principle calculation, we find that the ultraviolet emission is ascribed to band-edge emission of $\mathrm{CsPb}_{2} \mathrm{Br}_{5}$, which has a bandgap of $3.13 \mathrm{eV}$. The visible emission at $515 \mathrm{~nm}$ that was previously ascribed to band edge emission of $\mathrm{CsPb}_{2} \mathrm{Br}_{5}$ is now unambiguously assigned $\mathrm{CsPbBr}_{3}$, which emerged as a by-product due to thermally induced phase conversion between $\mathrm{CsPb}_{2} \mathrm{Br}_{5}$ and $\mathrm{CsPbBr}_{3}$. This study not only clarifies the luminescence mechanism of $\mathrm{CsPb}_{2} \mathrm{Br}_{5}$ being under debate, but also provides valuable insights for the development of $\mathrm{CsPb}_{2} \mathrm{Br}_{5}$ based optoelectronic devices.

\section{Conflicts of interest}

There are no conflicts to declare.

\section{Acknowledgements}

This work has been supported by National Natural Science Foundation of China (No. 11174071, 11304088 and 51372180) and Special Technical Innovation Project of Hubei Province (No. 2016AAA035).

\section{Notes and references}

1 W. S. Yang, B. W. Park, E. H. Jung, N. J. Jeon, Y. C. Kim, D. U. Lee, S. S. Shin, J. Seo, E. K. Kim, J. H. Noh and S. I. Seok, Science, 2017, 356, 1376.

2 A. Kojima, K. Teshima, Y. Shirai and T. Miyasaka, J. Am. Chem. Soc., 2009, 131, 6050-6051.

3 J. B. You, L. Meng, T. B. Song, T. F. Guo, Y. Yang, W. H. Chang, Z. R. Hong, H. J. Chen, H. P. Zhou, Q. Chen, Y. S. Liu, N. D. Marco and Y. Yang, Nat. Nanotechnol., 2016, 11, 75.

4 Q. D. Tai, P. You, H. Q. Sang, Z. K. Liu, C. L. Hu, H. L. W. Chan and F. Yan, Nat. Commun., 2016, 7, 11105.

5 W. Z. Li, W. Zhang, S. V. Reenen, R. J. Sutton, J. D. Fan, A. A. Haghighirad, M. B. Johnston, L. D. Wang and H. J. Snaith, Energy Environ. Sci., 2016, 9, 490.

6 G. Niu, X. Guo and L. Wang, J. Am. Chem. Soc., 2015, 3, 89708980.

7 T. A. Berhe, W. N. Su, C. H. Chen, C. J. Pan, J. H. Cheng, H. M. Chen, M. C. Tsai, L. Y. Chen, A. A. Dubale and B. J. Hwang, Energy Environ. Sci., 2016, 9, 323-356.

8 N. Yantara, S. Bhaumik, F. Yan, D. Sabba, H. A. Dewi, N. Mathews, P. P. Boix, H. V. Demir and S. Mhaisalkar, J. Phys. Chem. Lett., 2015, 6, 4360.

9 S. W. Eaton, M. Lai, N. A. Gibson, A. B. Wong, L. Dou, J. Ma, L. W. Wang, S. R. Leone and P. D. Yang, Proc. Natl. Acad. Sci. U. S. A., 2016, 113, 1993.

10 J. Xue, Y. Gu, Q. S. Shan, Y. S. Zou, J. Z. Song, L. M. Xu, Y. H. Dong, J. H. Li and H. B. Zeng, Angew. Chem., Int. Ed., 2017, 56, 5232.

11 L. Protesescu, S. Yakunin, M. I. Bodnarchuk, F. Krieg, R. Caputo, C. H. Hendon, R. X. Yang, A. Walsh and M. V. Kovalenko, Nano Lett., 2015, 15, 3692.

12 K. H. Wang, L. Wu, L. Li, H. B. Yao, H. S. Qian and S. H. Yu, Angew. Chem., Int. Ed., 2016, 55, 8328.

13 X. S. Tang, Z. P. Hu, W. Yuan, W. Hu, H. B. Shao, D. J. Han, J. F. Zheng, J. Y. Hao, Z. G. Zang, J. Du, Y. X. Leng, L. Fang and M. Zhou, Adv. Opt. Mater., 2016, 5, 1600788.

14 X. L. Zhang, B. Xu, J. B. Zhang, Y. Gao, Y. J. Zheng, K. Wang and X. W. Sun, Adv. Funct. Mater., 2016, 26, 4595.

15 G. P. Li, H. Wang, Z. F. Zhu, Y. J. Chang, T. Zhang, Z. H. Song and Y. Jiang, Chem. Commun., 2016, 52, 11296. 
16 J. Liang, C. X. Wang, Y. R. Wang, Z. R. Xu, Z. P. Lu, Y. Ma, H. F. Zhu, Y. Hu, C. C. Xiao, X. Yi, G. Y. Zhu, H. L. Lv, L. B. Ma, T. Chen, Z. X. Tie, Z. Jin and J. Liu, J. Am. Chem. Soc., 2016, 138, 15829-15832.
17 K. Nitsch, V. Hamplova, M. Nikl, C. Canale, K. Polak and M. Rodova, Chem. Phys. Lett., 1996, 258, 518-522.

18 X. M. Li, Y. Wu, S. L. Zhang, B. Cai, Y. Gu, J. Z. Song and H. B. Zeng, Adv. Funct. Mater., 2016, 26, 2435. 